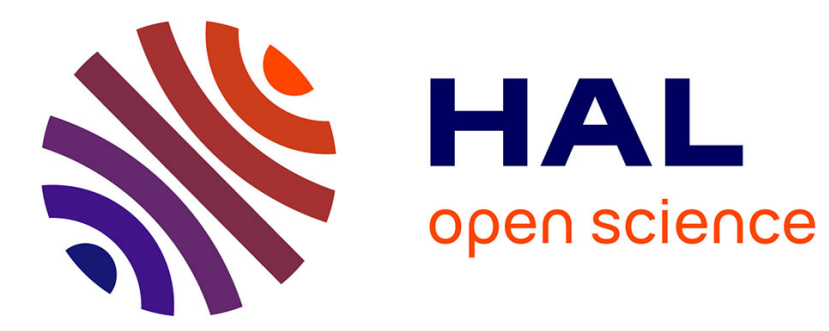

\title{
Description of an interferometric photothermal microscope and its application to the study of semiconductor samples
}

Karsten Haupt, A. Glazov, H. Walther, E. Döpel

\section{To cite this version:}

Karsten Haupt, A. Glazov, H. Walther, E. Döpel. Description of an interferometric photothermal microscope and its application to the study of semiconductor samples. Journal de Physique IV Proceedings, 1994, 04 (C7), pp.C7-11-C7-14. 10.1051/jp4:1994703 . jpa-00253144

HAL Id: jpa-00253144

https://hal.science/jpa-00253144

Submitted on 1 Jan 1994

HAL is a multi-disciplinary open access archive for the deposit and dissemination of scientific research documents, whether they are published or not. The documents may come from teaching and research institutions in France or abroad, or from public or private research centers.
L'archive ouverte pluridisciplinaire HAL, est destinée au dépôt et à la diffusion de documents scientifiques de niveau recherche, publiés ou non, émanant des établissements d'enseignement et de recherche français ou étrangers, des laboratoires publics ou privés. 


\title{
Description of an interferometric photothermal microscope and its application to the study of semiconductor samples
}

\author{
K. Haupt, A. Glazov, H.G. Walther and E. Döpel* \\ Institut für Optik und Quantenelektronik, Friedrich-Schiller-Universität, Max-Wien-Platz 1, 07743 Jena, \\ Germany \\ * Fraunhofer-Institut für Angewandte Optik und Feinmechanik, Schillerstrasse I, 07745 Jena, Germany
}

\begin{abstract}
A computerized scanning microscope is described which is equipped with a photothermal sensor. Two types of sensors have been developed both being based on probing the thermal lens above the heating spot by a Mach-Zehnder interferometer.

One interferometer was built up from separate optical components while the other one was designed as a microoptical block connected by a gradient index lens and optical fibres with a laser diode and a photodiode. Measurements from structured semiconductors are presented demonstrating the performance of the photothermal microscope.
\end{abstract}

\section{MEASURING PRINCIPLE}

For obtaining photothermal images from solid state samples on a microscopic scale we used a kind of laser scanning microscope which was additionally equipped with a photothermal sensor. The detection of local sample surface heating due to a modulated heating beam absorption was achieved interferometrically. We used a Mach-Zehnder probe beam arrangement where the interfering rays run parallel to sample surface, and one of the rays crosses the thermal lens above the heating spot.

Comparing this method with single-beam Mirage technique we get remarkable higher Signal-to-NoiseRatios (SNR) as shown in Fig.1. However, this advantage reduces at increasing modulation frequencies. In distinction to the Mirage technique the interferometric measurement is hardly affected by pointing noise and intensity fluctuations of the probe beam. Keeping SNR the same the interferometric detection enables higher scanning rates than single-beam techniques.

\section{SETUP OF THE MICROSCOPE}

Fig. 2 shows the basic design of the used photothermal microscope. An acousto-optically modulated $2 \mathrm{~W}$ Ar-Laser is coupled into a home-made Laser-scanning microscope consisting of a reflected light microscope which is equipped with galvano-scanners for heating beam deflection. The heating spot can be observed visually. The reflected heating beam is collected by the objective and detected by a photomultiplier, producing optical images. The thermal waves above the sample surface under test are probed by an appropriately positioned phothothermal interferometer whose signal together with the photomultiplier signal is fed into a two-phase lock-in amplifier connected with a PC. The PC stores both amplitude and phase signals and optical images, it controls sample position, modulation frequency and mirror-scanner deflections. Designed software enables for the correction of different systematic measuring errors, as e.g. a small tilt between sample surface and interferometer plane or local variations in optical absorptivity of the sample. The chosen type of detecting interferometrically the thermal lens by means of parallel probe beams allows for heating beam scanning along the probe beam direction. This beam scanning does not cause any sample vibration. Sample movement is only required for finding the next line scan position. 

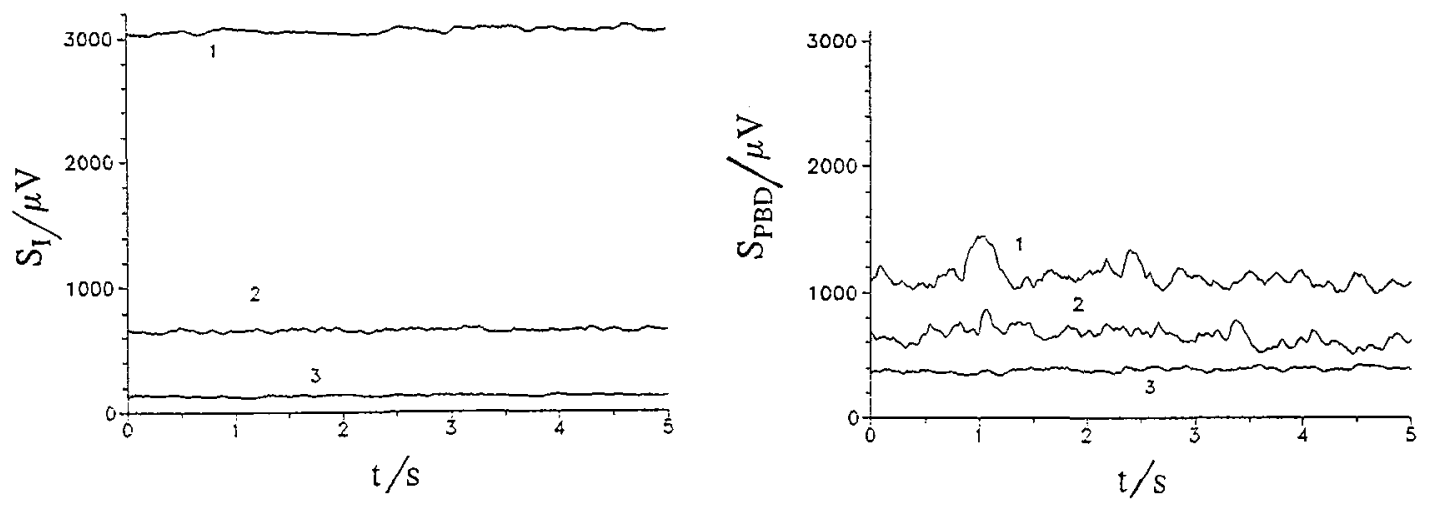

Fig.1: Comparison of interferometric $\left(S_{\downarrow}\right)$ and Mirage signal $\left(S_{\mathrm{PBD}}\right)$ on the same measuring conditions (probe beam radius $9 \mu \mathrm{m}$, heating beam radius $40 \mu \mathrm{m}$, vertical offset $40 \mu \mathrm{m}$ ) but at different frequencies: 1) $125 \mathrm{~Hz}, 2) 1.25 \mathrm{kHz}, 3) 12.5 \mathrm{kHz}$. The corresponding SNR are $17,4.5$ and 0.7 .

\subsection{Modular Design of a the Interferometer}

An appropriate interferometric set-up was already published in [1]. As shown in Fig.3 optical phase gratings (wavelength of some $10 \mu \mathrm{m}$ ) as probe beam splitters were used. The combination of different diffraction orders is performed by a lens, and working point adjustment can be achieved by shifting one of the gratings perpendicularely to the optical axis. By measuring the difference in light intensity of the +1 . and -1 . diffraction order behind the interferometer we are able to double the signal and to cancel out the unmodulated light. This results in a considerable increase of SNR.

The modular set-up requires an area of about $20 \times 30 \mathrm{~cm}^{2}$. It can be installed without any problem on the sample stage of the microscope.

\subsection{Microoptical Design of the Interferometer}

To decrease the size of the photothermal sensor and to increase its stability a compact microoptical set-up was designed as sketched in Fig.3. It consists of a glass plate to the front and the rear side of which integrated optical grating were glued. Through a monomode fibre and a sticked GRIN lens the probe laser beam was fed into the plate being diffracted from the entrance grating G1. The first diffraction order is reflected by a side plane of the plate and then it interferes with the zeroth order at the exit grating $\mathrm{G} 2$. Then this diffracted light can be analyzed by photodiodes.

The interferometer plate is directly put onto the sample surface under study which is illuminated through the plate by a focussed heating beam. Thermal waves also penetrate into the plate there modulating the interference pattern. To suppress thermal contact resistance at the glass-sample interface an immersion liquid should be used. Glycerine was found to be better than water, alcohol or optical immersion oil. The signal strongly depends on respective vertical offset between probe beam and heating spot position. This is illustrated in Fig. 4 where an immersed record is radially scanned along its surface showing the surface profile with individual grooves. Making the interference plate from materials with high thermal conductivity as sapphire or some fluorides will increase the photothermal sensitivity decisively.

As a peculiarity the signal of the interferometer sensitively depends on the d.c. temperature of the interferometer plate. This temperature increases when the sample is heated periodically, and it leads to a shift of the operating point. If the rise in d.c. temperature is high enough the working point leaves the linear range of the interferometer operation and may pass the turning points of the characteristic curve. At the same time the signal becomes nonlinearly distorted and can even change its sign. This shift of operating point along the interferometer characteristic has to be taken into account when we switch on the heating laser beam or increase its intensity or when we vary the modulation frequency. On the other hand by carefully observing the time behavior of the signal (drift of the operating point) we will be able 
to estimate the d.c. sample temperature besides its surface temperature oscillation.

Fig.2: Scheme ofthe PC controlled photothermal microscope.

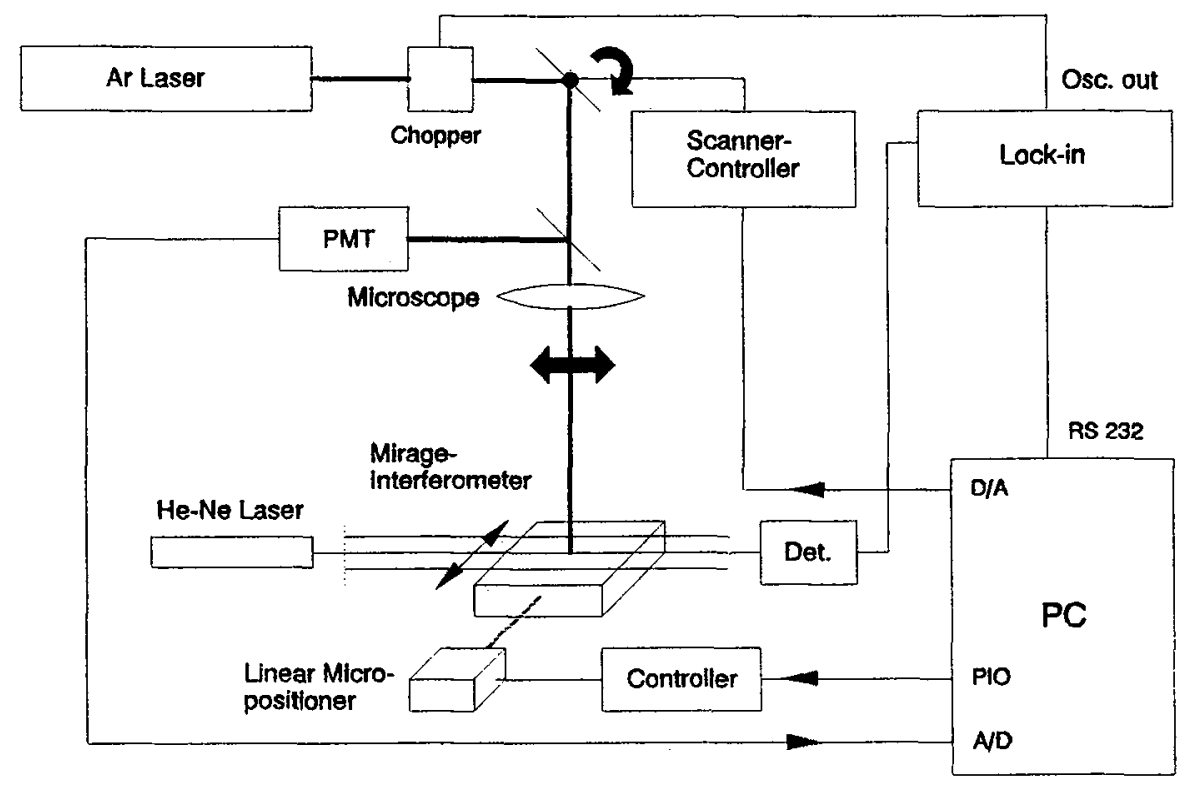

Fig.3: Scheme of the 2 types of investigated probe beam interferometers top: modular set-up with 2 phase gratings and 2 lenses bottom: microoptical interferometer with sticked ion e $\mathrm{x} \mathrm{h}$ anged phase gratings and fibre input
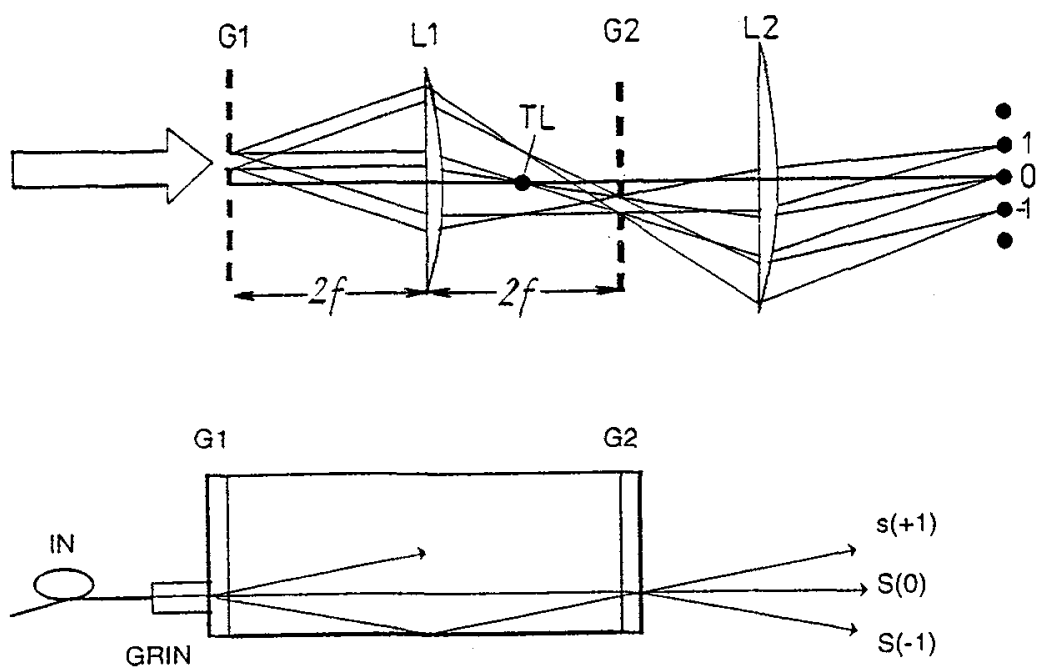

\section{SELECTED RESULTS}

Photothermal images from structured semiconductor and metal samples have been obtained by means of a scanning microscope with modular or microoptical sensor. The results demonstrate the following advantages of the described microscope: Easy selection of sample details of interest, comparability of optical and photothermal images, nearly signal independence on the optical behavior and the microprofile of the surface under study.

By means of the microoptical sensor line scans have been performed along the surface of silicon which 
partly was etched to create a porous film. Such porous $\mathrm{Si}$ shows optical and thermal properties quite different from crystalline silicon. Results for Ar- and YAG-laser heating are given in Fig.5. They illustrate the predominant influence of surface modification due to the porous layer when using infrared heating. The high signal contrast between crystalline and porous surface allows for the photothermal characterization of thin porous Si layers.

Fig.4: An immersed record is radially scanned along its surface. Top: amplitude, bottom: phase. Meas ured at 5 and $15 \mathrm{~Hz}$.

Fig.5: Line scan across a partly etched (porous) Si surface. dots:Ar-laser; $70 \mathrm{~Hz},+$ : YAGlaser, $70 \mathrm{~Hz}$; *: YAG-laser, $500 \mathrm{~Hz}$, : YAG-laser, $1 \mathrm{kHz}$.

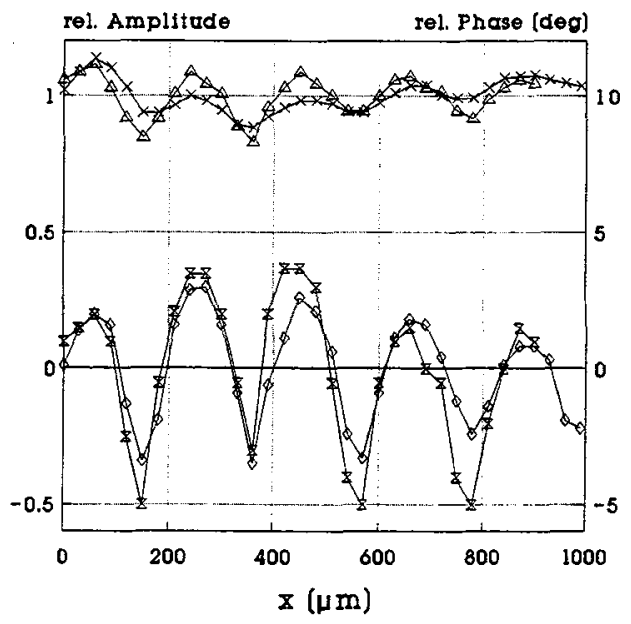

rel. Amplitude

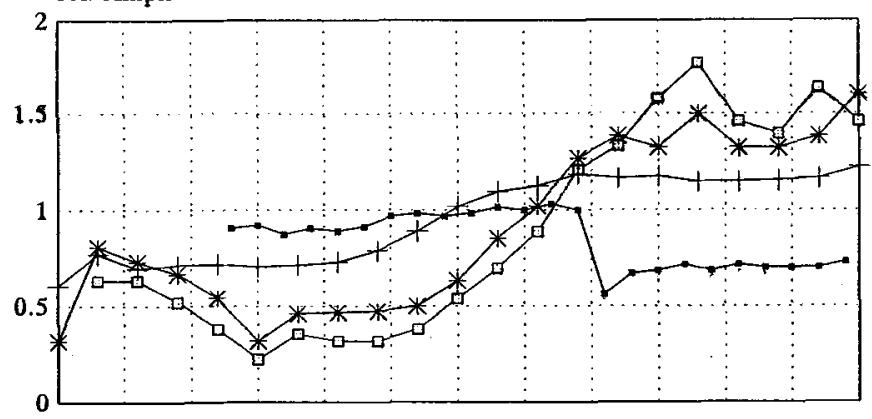

rel. Phase [deg]

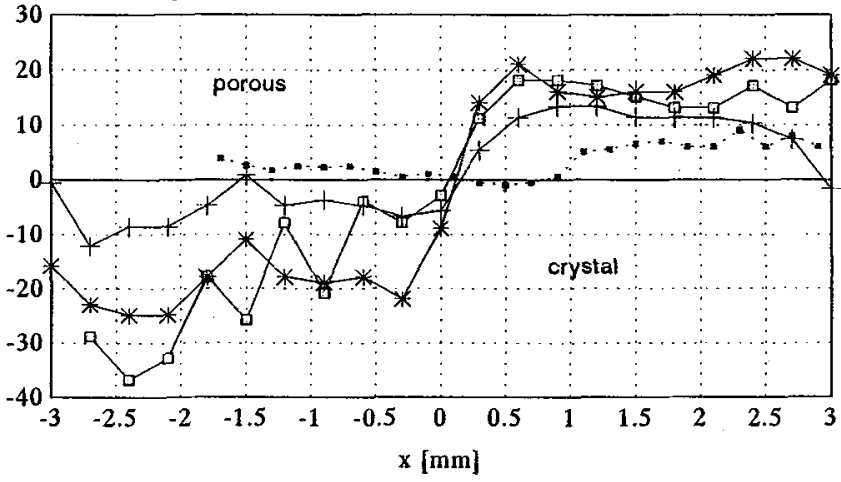

The authors wish to gratefully acknowledge the financial support of the Deutsche Forschungsgemeinschaft (DFG) and of the Alexander-von-Humboldt-Stiftung.

[1] H.G.Walther, K.Friedrich, K.Haupt, K.Muratikov, A.Glazov, Appl.Phys.Lett. 57 (1990), 1600-1601 